\title{
Reservas indígenas e fronteiras agrícolas na Chapada dos Parecis (MT): uma análise temporal por imagens TM-LANDSAT
}

\author{
IRIS DE MARCELHAS E SOUZA e PAULO RoBERTO MARTINI
}

A REgiÃo da Chapada dos Parecis, estado do Mato Grosso, vem sendo submetida desde o início da década de 60 a um acelerado processo de ocupação, fruto da expansão das fronteiras agrícolas para a Amazônia Ocidental. Os eixos principais são duas estradas federais: a BR 364 que, deixando Cuiabá no Mato Grosso, se estende atualmente até a fronteira com o Peru, passando por Porto Velho em Rondônia e Rio Branco no Acre; a BR 163 que, deixando Cuiabá, segue para Santarém no estado do Pará. As estradas foram perenizadas em meados dos anos 60 para uma rápida interiorização da parte da Amazônia Legal compreendida pelos estados do Mato Grosso, Rondônia e Acre.

Em se tratando de um ambiente geomórfico apropriado para desenvolvimento de agricultura ostensiva e mecanizada, os Parecis foram aceleradamente ocupados por grandes propriedades agrícolas dedicadas principalmente à cultura de grãos como soja e arroz. Neste processo também aconteceu o estabelecimento rápido de novos municípios, uma grande parte deles com menos de 30 anos, como Comodoro, Sapezal, Juína, Campos Novos, Sinop, Sorriso e tantos outros, criados a partir dos eixos de ocupação instalados pelos rodovias mencionadas.

A instalação dos municípios trouxe a necessidade também de se estabelecer limites para as reservas indígenas a fim de serem preservadas sua cultura e sua natividade. Assim, no estabelecimento da diretriz original da BR 364, ou seja, no planejamento da rodovia o traçado se preocupava com os limites de algumas reservas já então definidas como por exemplo a Reserva Nambikwara, talvez a maior dos Parecis. A Reserva Enawene-Nawê foi outra área de preservação dos Parecis, criada mais para o final da década de 70, com limites controlados em parte pela importante rodovia estadual (MT 319) que liga Vilhena a Juína. Ambas são exemplos de reservas cujos limites 
foram estabelecidos no contexto da expansão acelerada da fronteira agrícola da Amazônia Ocidental.

Notícias recentemente veiculadas por jornais (Cubas, 1998) dão conta de que as reservas dos Parecis estão por sofrer impactos, frutos da dinâmica de ocupação agrícola do entorno, principalmente nos municípios de Juína, Sapezal e Comodoro. Com base nestes fatos e tendo-se em conta que a área compreendida por tais municípios tem sido motivo de nossos estudos para conhecimento da distribuição espacial da cultura de soja, tomou-se a iniciativa de se analisar temporalmente a expansão das áreas agrícolas e a relação delas com os limites das reservas mencionadas.

Neste trabalho apresentam-se os procedimentos metodológicos e os principais resultados obtidos na análise temporal, por imagens LANDSAT, da expansão da fronteira agrícola nos Parecis e de sua relação espacial com as fronteiras das reservas indígenas Nambikwara e Enawene-Nawê.

\section{Área de estudo}

A região está incluída entre as coordenadas 60. e 59. de longitude Oeste e $11: 50$ e 14 de latitude Sul. Seus limites seguem a BR 364 entre as sedes dos municípios de Comodoro no Mato Grosso e Vilhena em Rondônia, prosseguindo daí para Juína pela rodovia MT 319. Os limites a Leste são definidos pelo rio Juína e, posteriormente, pelo rio Juruena. A área se situa ao longo do eixo central da Chapada dos Parecis, divisor de águas do rio Juruena com o rio Guaporé.

\section{Materiais}

As imagens de satélite que cobrem a área correspondem aos WRS $229 / 68$ e 228/68 ambos deslocados de seis segundos para Sul. As imagens selecionadas dataram respectivamente de junho-84 (229/68), maio-84 e junho-97 (228/68). O produto selecionado correspondeu ao código 2463 , ou seja, cena inteira com correção geométrica básica, nível 4, em bandas $3,4,5$, CD ROM formato INPE. Foram também utilizadas imagens coloridas em papel fotográfico na escala l: 250.000 de 1992.

Os limites das duas reservas foram extraídos do Mapa da Amazônia Legal, escala 1:3.000.000, publicado pela Fundação IBGE em 1995. Cartas topográficas na escala 1:250.000, também do IBGE, foram usadas para a correção geométrica das imagens.

Como ferramenta para integração e manipulação dos dados, optou-se pelo uso do SPRING - Sistema de Processamento de Informações geo- 
referenciadas, por atender às necessidades do presente trabalho e também por ser um sistema amigável.

\section{Metodologia}

\section{Digitalização das áreas das reservas}

Devido à indisponibilidade de dados cartográficos em escala maior foi usado, como base para delimitação das áreas das reservas, um mapa na escala 1:3000.000 da FIBGE. Esses dados originalmente na projeção policônica, foram convertidos para a projeção UTM, uma vez que esta foi a projeção das cartas topográficas básicas da área de estudo.

\section{Correção geométrica das imagens}

As imagens digitais estão sujeitas à uma série de distorções espaciais e não possuem precisão cartográfica quanto ao posicionamento dos objetos nelas apresentados. É necessário aplicar correções que vão reorganizar essas informações em relação a um sistema de projeção cartográfica; para tanto, são identificadas feições na imagem, que possuem um correspondente na carta topográfica, tornando possível saber as coordenadas dessas feições. Esse processo foi realizado tendo como base as cartas topográficas da FIBGE na escala $1: 250.000$.

\section{Processamento das imagens}

- Aumento linear de contraste: técnica de processamento que permite ampliar o intervalo dos níveis de cinza da imagem original para toda escala de níveis de cinza disponíveis, que no caso da imagens TM corresponde a 256 níveis. Essa técnica, permite melhorar a qualidade visual das imagens.

- Modelo linear de mistura espectral: a radiância de um pixel em uma imagem de satélite é a integração da radiância detectada por todos os elementos presentes no pixel. É possível gerar imagens sintéticas que vão representar a proporção de cada elemento dentro de um pixel. Esse processo é feito por meio do modelo linear de mistura espectral (Shimabukuro \& Smith, 1995) ao selecionar-se amostras de solo, vegetação e sombra sobre as quais foram obtidas três imagens representando as frações de cada uma das componentes presentes nas imagens originais. Esse processo foi utilizado para identificar o tipo de ocorrência no interior dos polígonos de desmatamento no que se relaciona com maior ou menor densidade de vegetação. 


\section{Análise dos resultados}

\section{Quanto à metodologia}

A metodologia adotada mostrou-se adequada para a identificação das áreas de desmatamento e possibilitou o reconhecimento de padrões de uso dentro das reservas, que se assemelham aos padrões externos de uso do solo.

Após os processos de digitalização, correção geométrica e tratamento das imagens, foi possível observar que as utilizadas se mostraram eficientes para evidenciar as mudanças ocorridas na área em questão. Houve desmatamento de áreas pertencentes à reserva dos Enawene-Nawê, conforme demonstrado nas figuras 1 e 2 .

\section{Houve desmatamento} de áreas pertencentes à reserva dos Enawene-Nawê...

Essas áreas desmatadas pos-

suem o mesmo padrão de áreas cultivadas fora da reserva. É possível observar também que as áreas cultivadas fora das reservas se estendem em direção às fronteiras noroeste e nordeste desta reserva.

\section{O desmatamento}

dentro da área da reserva

foi significativo...

A reserva em questão, possui aproximadamente 568 mil ha, sendo observado que em um período de 13 anos que separam as datas analisadas (19841997) o aumento de desmatamento dentro da área da reserva foi significativo, conforme pode ser observado no quadro apresentado a seguir e visualizado nas figuras 3 e 4 .

Total de áreas desmatadas

\begin{tabular}{|c|c|}
\hline Ano & $\begin{array}{c}\text { Total aproximado da } \\
\text { área desmatada (em ha) }\end{array}$ \\
\hline 1984 & 668 \\
\hline 1997 & 8000 \\
\hline
\end{tabular}




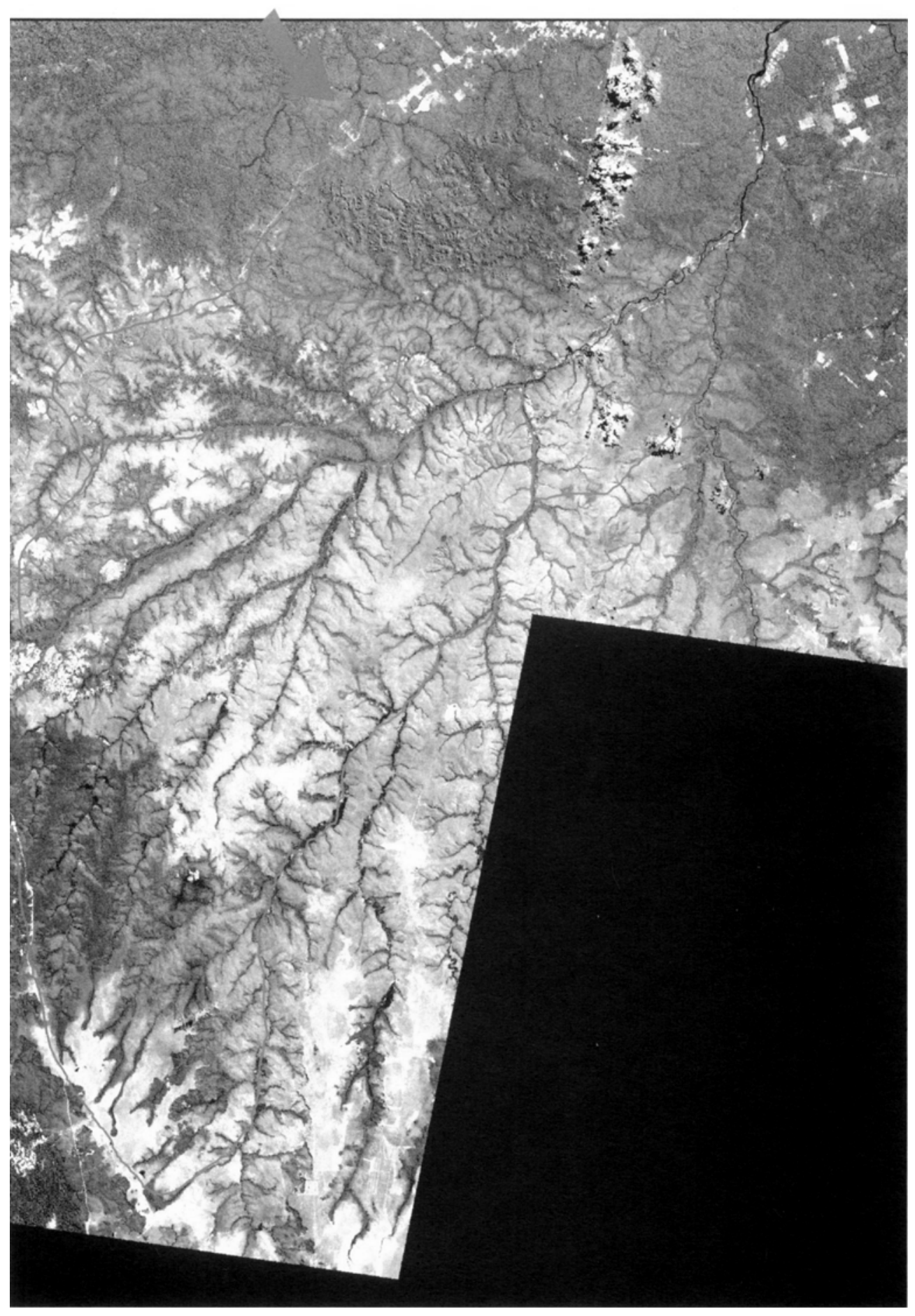

Figura 1

Imagem TM - 228-68/229-68/229-69 - Banda 5 - 1984 - Esc. Aprox. $1 \backslash 1500000$ 


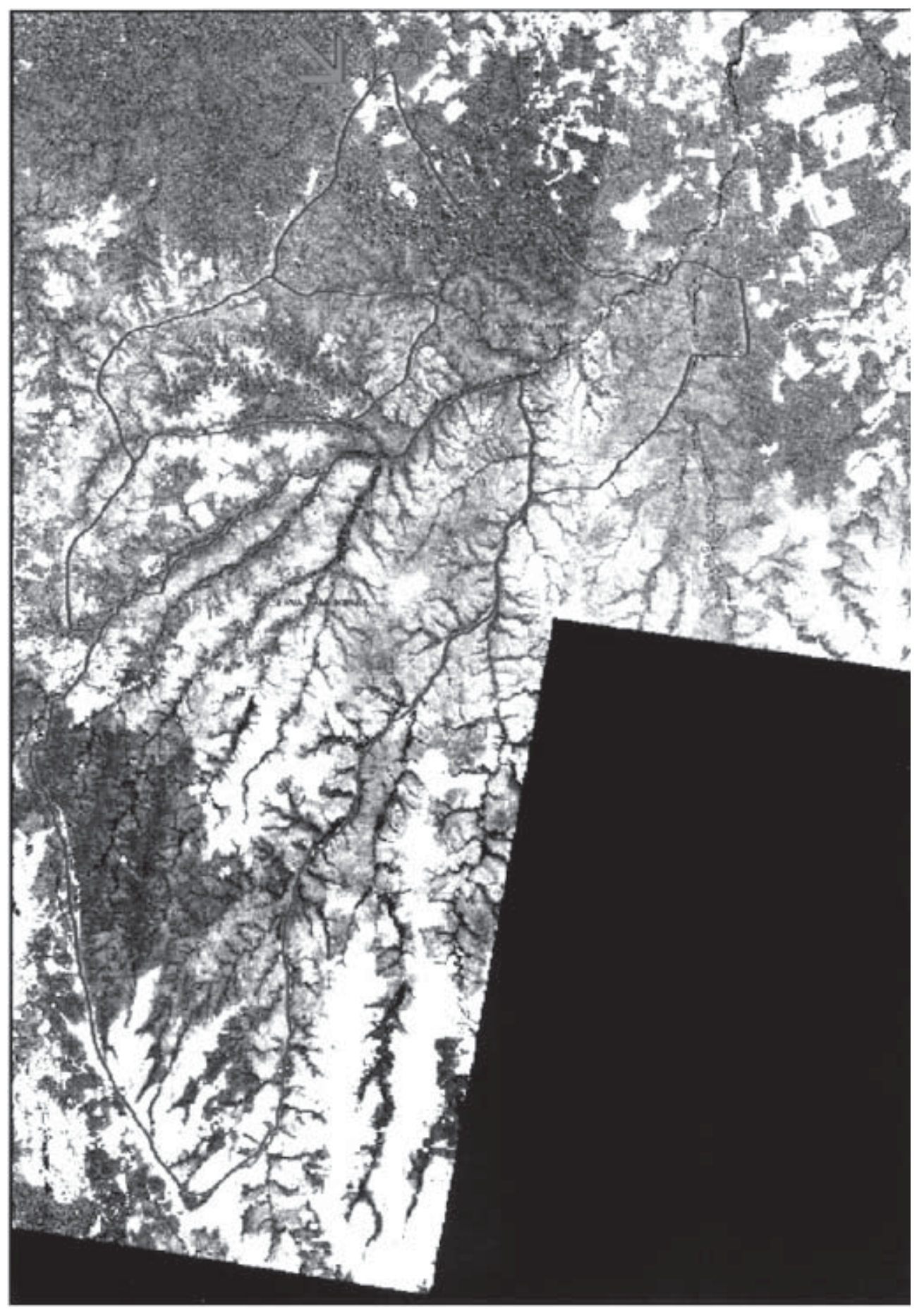

Figura 2

Imagem TM - 228-68/229-68/229-69 - Banda 5 - 1997 - Esc. Aprox. $\backslash \backslash 1500000$ 


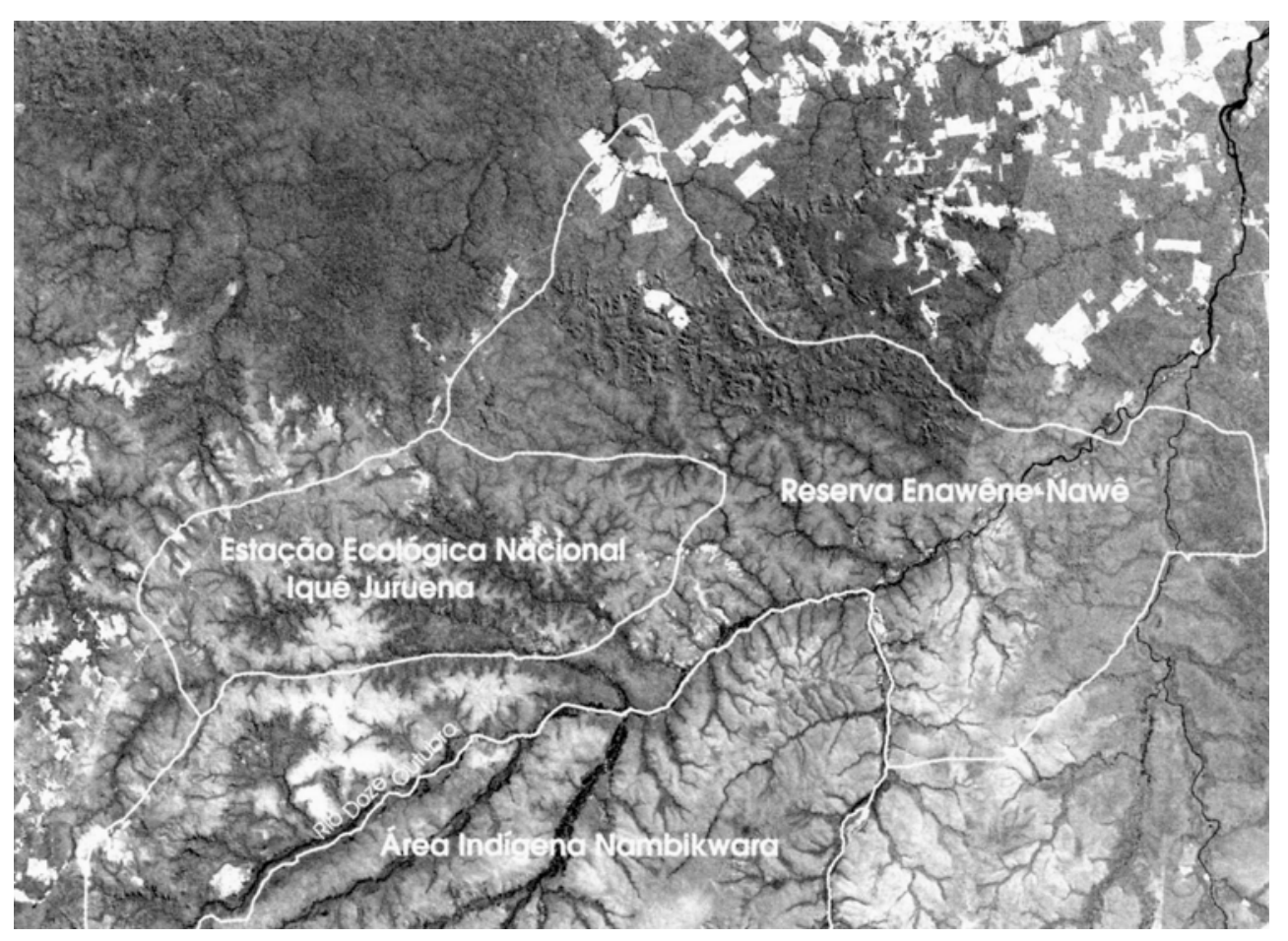

Figura 3

Imagem TM - 228-68/229-68 - Banda 5 - 1997 (área desmatada em destaque)

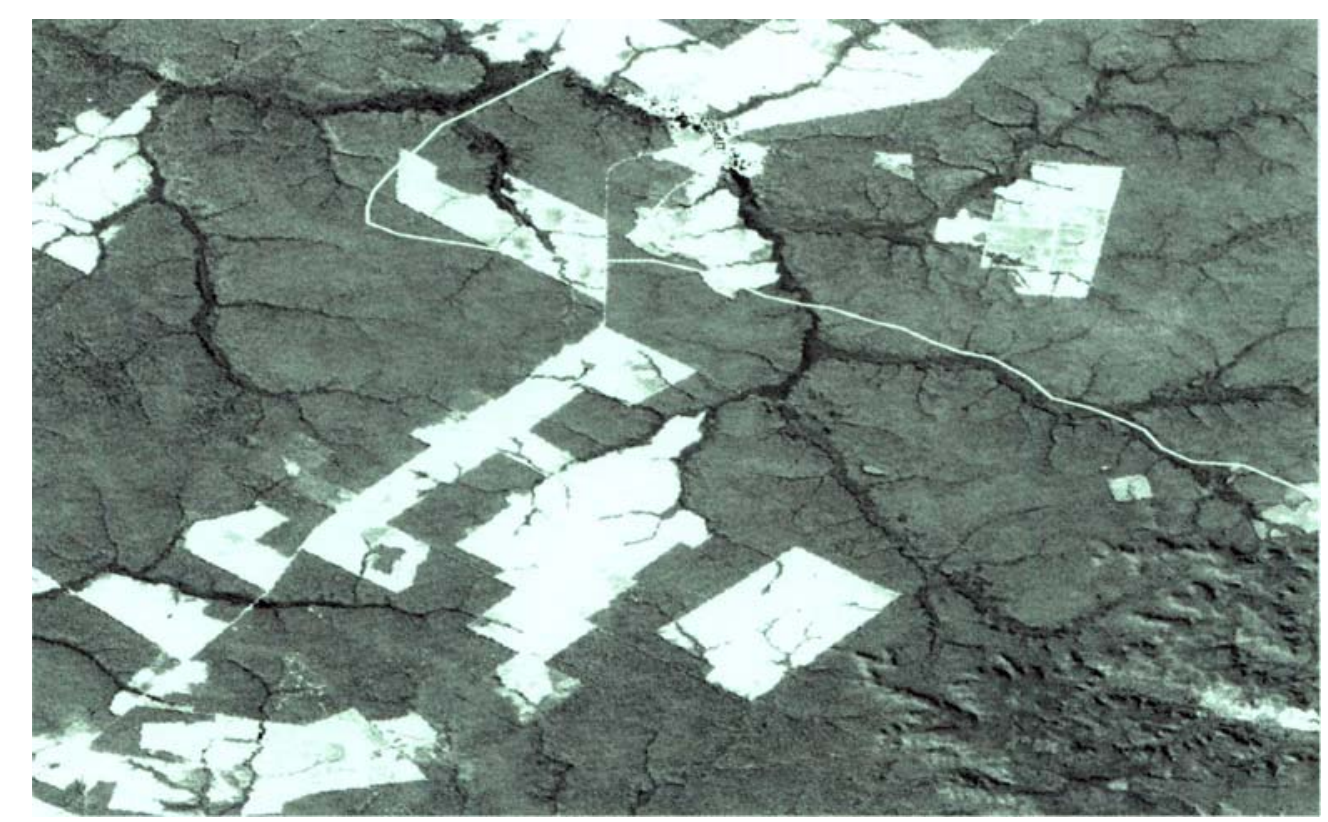

Figura 4

Imagem TM - 229-68 - Banda 5 - 1997

(zoom da área desmatada dentro e fora dos limites da reserva Enawene-Nawê) 
Como resultado da aplicação do modelo linear de mistura espectral, obteve-se três imagens frações das componentes vegetação, solo e sombra (água), as quais permitiram fazer as seguintes análises: na imagem fração da componente vegetação (figura 5) as áreas com níveis de cinza mais claras indicam maior presença de vegetação. Observa-se que as áreas referentes aos polígonos de desmatamento representam porções mais escuras que o restante das áreas, com exceção de pequenas áreas já em estado de recuperação. A imagem fração da componente sombra (figura 6) apresentou uma uniformidade nos níveis de cinza para a área de floresta contínua, com variações nas áreas desmatadas. A influência desta componente pode ser melhor observada ao longo da drenagem, onde os níveis de cinza são mais claros, pois apresentam outro tipo de vegetação (mata galeria). A imagem fração da componente solo (figura 7) mostra, em níveis de cinza mais claros, as áreas desnudas ou com menor densidade de vegetação. A aplicação do modelo possibilita ainda observar a composição colorida da figura 8 , onde a componente vegetação é representada pelo verde, a componente solo pelo vermelho e a componente sombra pelo azul, onde a variação na tonalidade de cores possibilita perceber a influência de cada componente do modelo na área de interesse e mais uma vez evidenciar a padronização do uso do solo dentro da reserva com o uso externo do solo em área de fronteira.

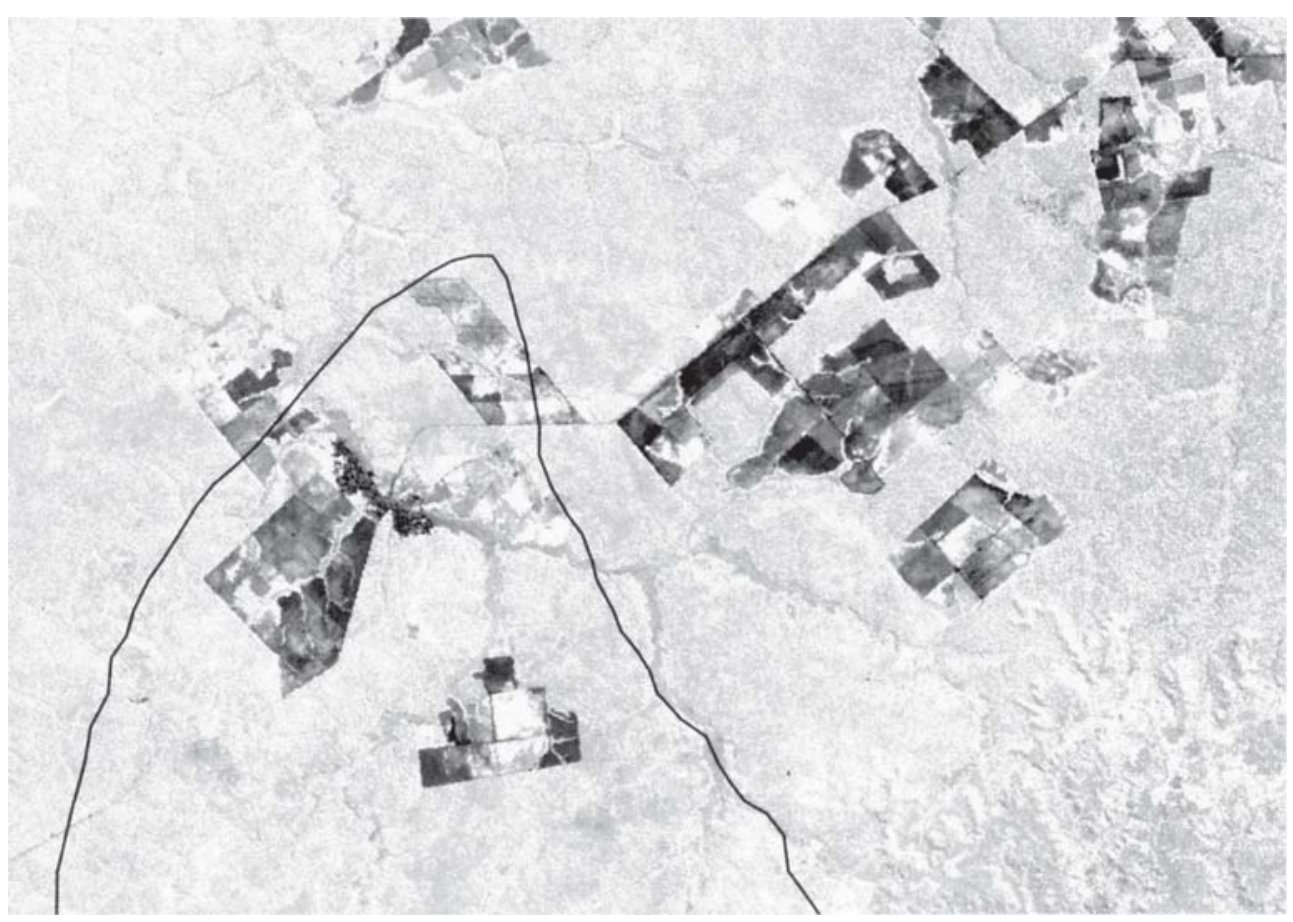

Figura 5

Imagem Fração da Componente Vegetação

(zoom da área desmatada) escala aprox. 1:200.000 


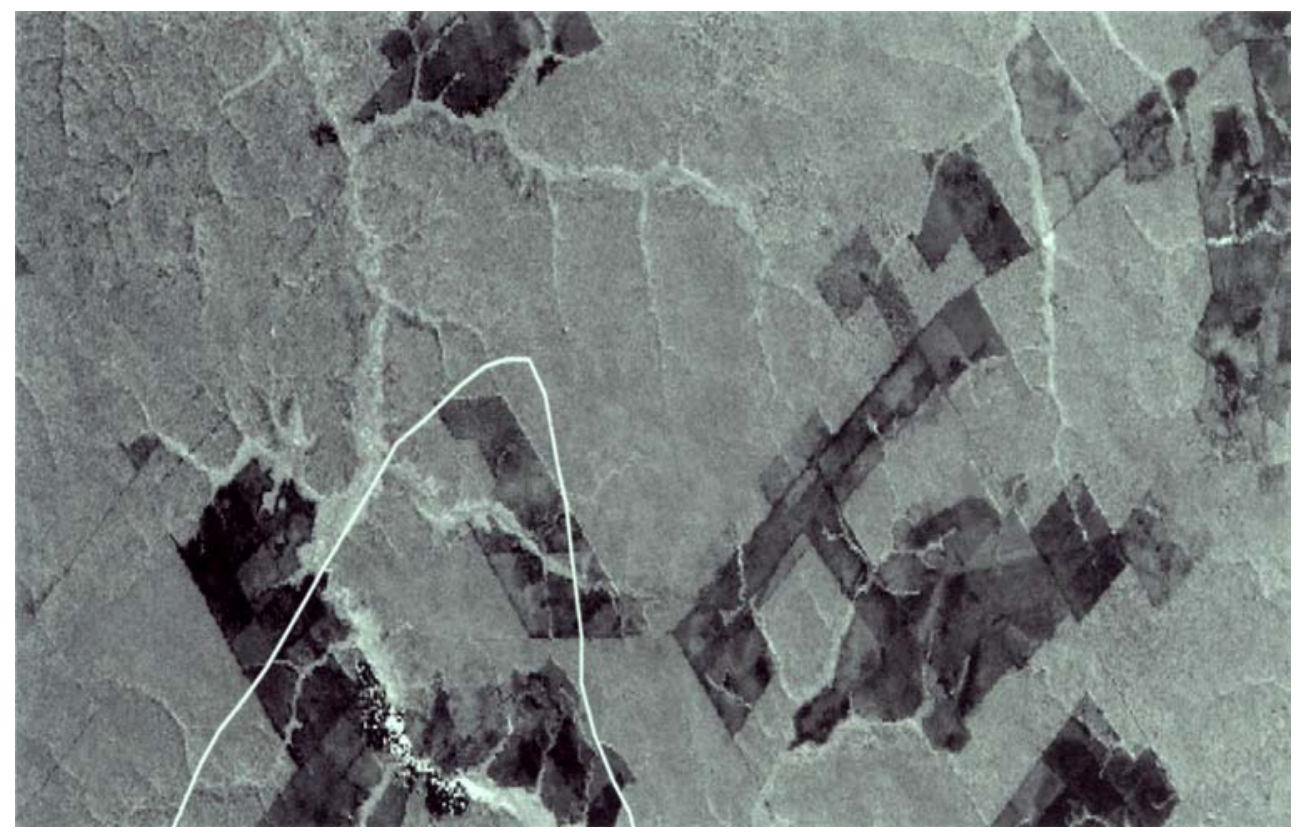

Figura 6

Imagem Fração da Componente Sombra (zoom da área desmatada) escala aprox. 1:200.000

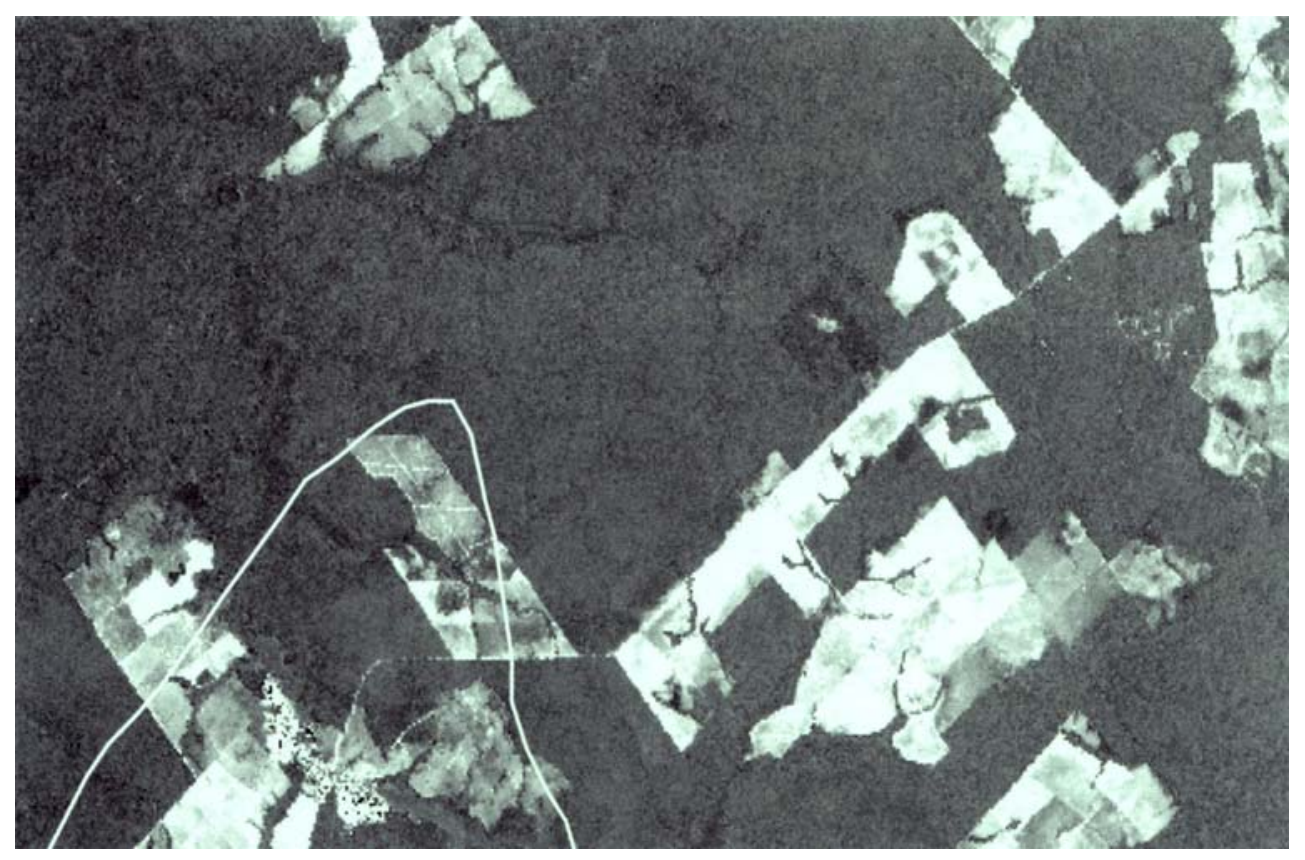

Figura 7

Imagem Fração da Componente Solo (zoom da área desmatada) escala aprox. 1:200.000 


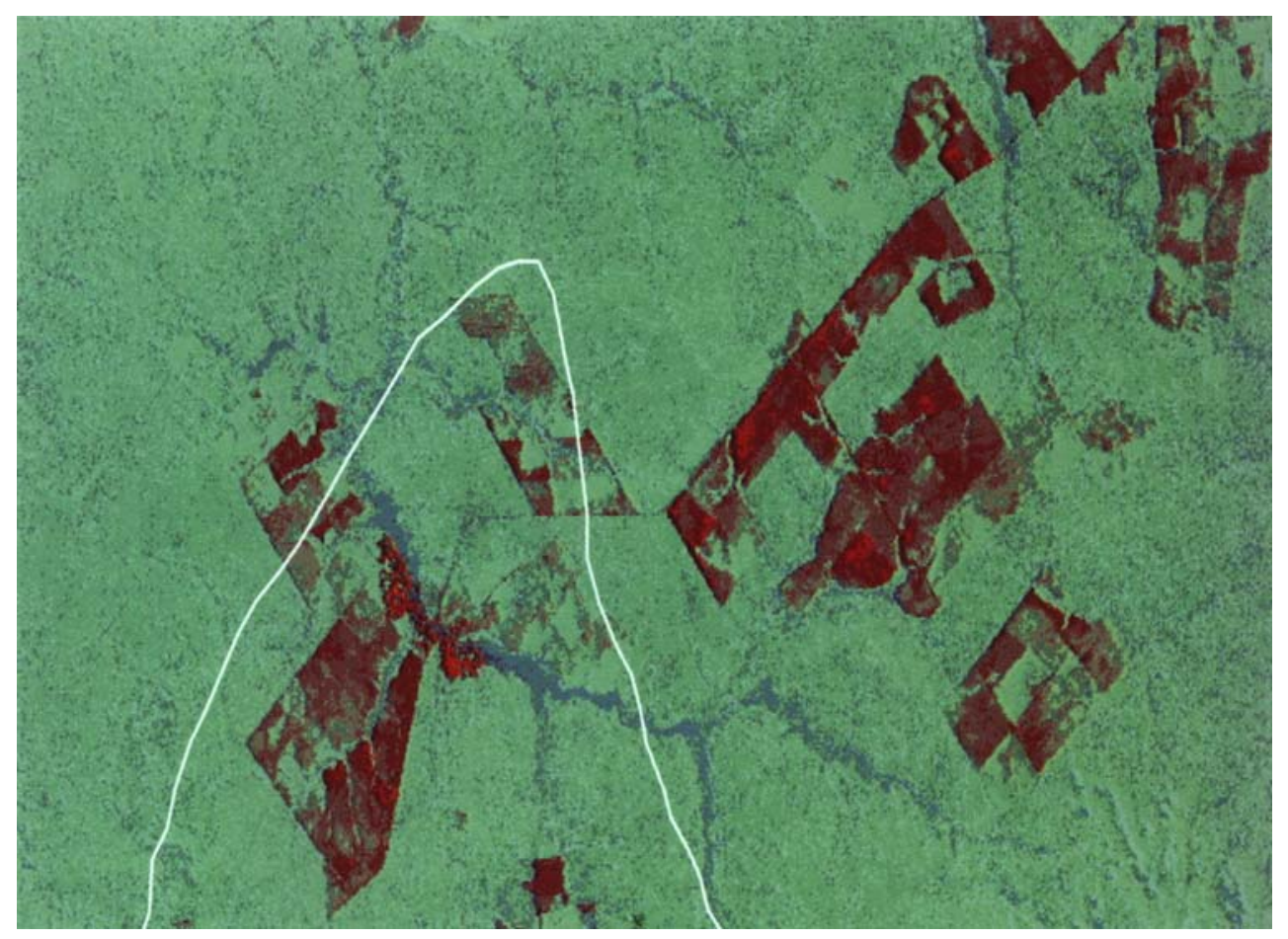

Figura 8

Composição Colorida das Componentes Solo (vermelho),Vegetação (verde) Sombra (azul) (zoom da área desmatada) escala aprox. 1: 200.000

\section{Análise regional}

Em nível geral, a análise temporal mostrou que as reservas indígenas estudadas sofrem diferentes tipos de assédio por parte do entorno agrícola. Pode-se perceber que as fronteiras das reservas próximas de agricultura ostensiva desenvolvida sobre chapadas em grandes propriedades não sofreram invasões. Em fronteiras estabelecidas nas vizinhanças de propriedades pequenas, onde os relevos são mais acidentados de forma que inibem a agricultura extensiva, as pressões são maiores e as invasões efetivamente ocorrem.

Os vetores dessa pressão, e mesmo da invasão, são as estradas. Se as rodovias federais passam ao largo ou eventualmente acompanham alguns limites, não são elas que efetivamente avançam ou se aproximam das bordas das reservas. Mesmo as rodovias estaduais, que interiorizando mais o uso da terra provocam pressões fortes, não ultrapassam os limites estabelecidos das reservas. As vicinais são os principais vetores na medida que são decididas em nível de município, onde a influência de proprietários ou de exploradores é sempre forte. As invasões observadas neste trabalho foram sustentadas por vicinais (figura 7 ). 
Especificamente, cada reserva tem diferentes atributos quanto à sua distribuição espacial e a distribuição espacial dos padrões de uso da terra. Dessa maneira, torna-se mais adequado tratar também as reservas separadamente, como segue.

RESERVA INDÍGENA ENAWENE-NAWÊ. Foi criada nos anos 70 em função de que os primeiros contatos aconteceram também neste período. As imagens mostram que já em 1984 seus limites estavam sendo invadidos a partir da MT 319 e de suas vicinais no trecho noroeste, próximo da escarpa dissecada da Serra do Norte (figura 1). Os padrões de ocupação são semelhantes aos de Juína, nitidamente estendidos a partir daquela cidade. Estes padrões são típicos de atividade agropecuária a base de propriedades pequenas. A região está instalada em planalto dissecado com relevo muito ondulado, o que provoca o aparecimento de minifúndios com diferentes tipos de ocupação agrícola e com forte componente exploradora. Os padrões de exploração aparecem como extração de madeira e mesmo garimpos localizadamente. Na parte sudeste da reserva, entre os rios Juruena e Papagaio, existe proximidade com áreas ostensivamente agrícolas (soja) desenvolvidas principalmente no município de Sapezal. A fronteira desta monocultura ao longo do divisor Juruena-Sauenirá se aproximou $3,75 \mathrm{~km}$ da fronteira da Reserva desde 1992 e estavam, em 1997, a $25 \mathrm{~km}$ (figura 2). Nitidamente as fronteiras da soja não pressionam esta reserva por contato ou invasão. A fronteira leste da reserva mostra evidentes indicações de avanço de padrões de uso advindos de Brasnorte, cuja sede se encontra no alto divisor dos rios Papagaio e Sangue. Os limites da reserva não foram ultrapassados nesta região (figura 2).

Danos indiretos entretanto merecem ser referidos quanto aos recursos hídricos quer superficiais quer subterrâneos. No caso desta reserva as áreas de soja encontram-se a montante, desenvolvidas sobre rochas arenosas sub-horizontais ou com suave mergulho de 10 graus para norte-nordeste. Esta situação de rochas muito porosas, com drenagem superficial combinando em direção com o mergulho das camadas, estabelece um quadro geomórfico muito favorável para a disseminação dos resíduos nos mananciais hídricos da reserva. Isto porque toda sua parte oriental se encontra a jusante do Soja tanto no domínio superficial quanto no subterrâneo. Nas imagens não foi identificado nenhum tipo de atributo que mostre impacto nas águas. Verdadeiramente seria muito difícil que aparecesse pois as calhas dos rios são muito encaixadas e com densas matas ciliares. Análises das águas deveriam ser feitas para se conhecer melhor a situação dos mananciais da reserva. 
RESERVA NAMbikwara. Com nativos contatados no início do século $\mathrm{XX}$, não mostra áreas modificadas por invasões como aquelas detectadas na Reserva Enawene-Nawê. As imagens de 1997 mostram limites não-trespassados embora claramente seu entorno demonstre o avanço das fronteiras agrícolas, principalmente na chapada do divisor Juruena-Juína. Foi observado que a vicinal conduzindo a expansão agrícola nesta chapada atinge o picadão que marca o limite Nambikwara no divisor Formiga-Juruena. Na verdade esta situação foi observada já nas imagens em papel fotográfico de 1992. A imagem de 1997 não mostrou qualquer mudança da cobertura nativa neste setor dos limites, o que indica que a agricultura pode estar pressionando mas não está invadindo a reserva (figura 2). A mesma situação se observa ao longo do limite da reserva com a BR 364. Esta rodovia é o principal eixo de comunicação terrestre entre a Amazônia Oriental e as regiões Sul, Sudeste e Centroeste. Mesmo se tratando de uma borda de alta pressão, não aparece nas imagens nenhum padrão claro de ocupação. As bordas da reserva mantêm a cobertura vegetal nativa de cerrados. Os Nambikwaras têm sua região de domínio mantida praticamente intacta por mais de 80 anos. Seu primeiro contato com a civilização aconteceu durante a primeira missão aos Parecis, realizada por Rondon em 1915, de acordo com Untermeyer (1962).

Assim, como tratado na reserva Enawene-Nawê, a questão dos recursos hídricos também merece atenção, embora apenas e estritamente o Juruena percorra ao mesmo tempo limites de reserva e de domínio agrícola. Os demais rios que percorrem a reserva não têm conexões diretas com áreas agrícolas.

\section{Considerações finais}

Dos assuntos aqui discutidos, talvez quatro pontos mereçam ser enfatizados e algumas questões formuladas.

Os pontos principais são

- as invasões podem ser detectadas e pontos de alta pressão podem ser mapeados;

- a metodologia comporta o uso de SIG e de imagens de satélite com abordagem temporal;

- a expansão de vicinais deve ser monitorada;

- os padrões de uso do solo (agricultura ostensiva versus minifúndios de múltiplos usos) das invasões podem ser caracterizados (figuras 7 e 8 ). 
As questões importantes que devem levar os autores a dar continuidade a este trabalho se referem aos seguintes pontos:

- a Reserva Nambikwara, com mais de 80 anos desde a sua criação, tem seus limites e sua natureza preservadas enquanto a Reserva EnaweneNawê, com pouco mais de 30 anos, está invadida e com limites muito pressionados (figura 2);

- a invasão se dá mediante vicinais carregando minifúndios de múltiplos usos, nitidamente de caráter explorador. Nos limites próximos de agricultura extensiva das chapadas a invasão não ocorre na área de estudo;

- não ficou claro no levantamento bibliográfico realizado se os Parecis são formados por uma seqüência de arenitos de idade permo-carbonífera, ou por duas, a partir de uma segunda cobertura também arenosa de idade cretácea, como aliás acontece em outros grandes chapadões do Mato Grosso. No caso de existir essa cobertura cretácea, como parece acontecer na Reserva Enawene-Nawê, abre-se a perspectiva de serem encontrados ali ricos jazimentos fossilíferos de répteis, como aqueles descritos por Oliveira Roxo (1937). Trabalhos anteriores ao RADAMBRASIL (1980), como aqueles de Ab'Saber (1954) e de Scorza (1960), dão conta de que existem verdadeiramente na área dois tipos de chapadas suportadas por duas seqüências sedimentares. O prosseguimento dos trabalhos tratando também deste assunto iria valorizar mais ainda a preservação das reservas;

- os recursos hídricos superficiais afetados por agrotóxicos merecem ser analisados por meio de Sensoriamento Remoto. A tendência da concentração desses resíduos nos aqüíferos também é um item a ser estudado a partir dos atributos superficiais de cenas como a drenagem e o relevo.

Referências bibliográficas

AB'SABER, A.N. O planalto dos Parecis na região de Diamantino (Mato Grosso). Boletim Paulista de Geografia, n. 17, julho 1954.

CROSTA, A.P. Processamento digital de imagens de sensoriamento remoto. Campinas, IG/Unicamp, 1992.

CUBAS, A. Enawene-Nawês são ameaçados com o avanço da agricultura moderna. Jornal Diário de Cuiabá, Caderno Cidades, p. 15, março 1998. 
OLIVEIRA ROXO, M.G. Notas geológicas sobre a chapada de Matto Grosso. Notas preliminares e estudos. Rio de Janeiro, Serviço Geológico e Mineralógico - Ministério de Agricultura, 30 de maio 1937.

RADAMBRASIL. Folha SC 21 Juruena, v. 20, cap. Geologia, p. 23-116 e cap. Geomorfologia, p. 117-164. Rio de Janeiro, DNPM-Mme, 1980.

SCORZA, E.P. Geologia de Diamantino, Estado do Mato Grosso. Notas Preliminares e Estudos n.113. DNPM/DGM/Ministério da Agricultura, agosto 1960.

SHIMABUKURO, Y.E. \& SMITH, J.A. Fraction images derived from LANDSAT TM and MSs data for monitoring reforested areas. Canadian Journal of Remote Sensing, março 1995.

URTENMEYER, L. Os forjadores do mundo moderno, v. III, 1853-1868. São Paulo, Editora Fulgor, 1962, p. 717-724.

ABSTRACT - PARECIS Plateau in the State of Mato Grosso has been submitted to an intense process of occupation for the last thirty years. Through this work a temporal analysis is done on the borders of Nambikwara and Enawene-Nawê which are two of several other indian reservations that are distributed over the Parecis Plateau. The study analyses the spatial distribution of the reservation boundaries and the expanding nearer cropfields. TM-LANDSAT images collected in June of 1984 and May/June of 1997 are the main data support. The general procedures included: digitizing the reservation bounds; conforming cartographic bases and projections; registering images and maps; linear model of spectral mixture; analysis. Results show that the reservation boundaries are getting closer and are often trespassed by cropfields bounds. Trespassed boundaries were depicted in the northwestern edge of Enawene-Nawê along the route that links Vilhena to Juína (route MT 319). The spatial distribution of the roads in the region showed that the vicinals were the main vectors of the process that need to be continuously observed. The results allow recommending the application of the same procedures elsewhere in the country. The experience also allows anticipating that the same methodology can be used even for reservations poorly known or known just by preliminary surveys or descriptive memorials.

Iris de Marcelhas e Souza é geógrafa e Paulo Roberto Martini é geólogo. Ambos são funcionários do Instituto Nacional de Pesquisas Espaciais (INPE) e realizam atividades de pesquisa e aplicações nas áreas de sensoriamento e geoprocessamento.

Os autores agradecem a valiosa colaboração dos pesquisadores M.A. Moreira, L.C.N. Aulicino, J.L. Rodrigues, Yi Y.E. Shimabukuro e B.G.T. Rudorff. 